\title{
Turn Back Elevation of Once Reduced IOP After Trabeculotomy Ab Externo and Kahook Dual Blade Surgeries Combined with Cataract Surgery
}

This article was published in the following Dove Press journal: Clinical Ophthalmology

\author{
Etsuo Chihara $\mathbb{D}^{1,2}$ \\ Tomoyuki Chihara ${ }^{3}$ \\ 'Department of Ophthalmology, Sensho- \\ Kai Eye Institute, Uji, Kyoto, Japan; \\ ${ }^{2}$ Department of Ophthalmology, Shimane \\ University, Izumo, Shimane, Japan; \\ ${ }^{3}$ Department of Ophthalmology, Kansa \\ Medical University, Hirakata, Osaka, \\ Japan
}

Purpose: To evaluate the surgical outcome of internal trabeculectomy by Kahook dual blade (KDB) with that of external trabeculotomy, each combined with phaco-lensectomy and intraocular lens implantation (Phaco).

Patients and Methods: This is a retrospective comparative study. The primary and secondary outcome measures are postsurgical intraocular pressure and postsurgical hyphema. One eye each of 76 primary open angle glaucoma (POAG), pseudoexfoliation glaucoma (PEG) and ocular hypertension $(\mathrm{OH})$ patients underwent external phaco-trabeculotomy, and that of 40 POAG, PEG and $\mathrm{OH}$ patients underwent phaco-KDB surgery.

Results: Reduction of the intraocular pressure (IOP) by phaco-KDB at one and two years was 28.4 and $27.8 \%$, respectively, and was not significantly different from that by external phaco-trabeculotomy of $32.7 \%(P=0.256)$ and $31.5 \%(P=0.468)$, respectively. Three months postsurgical IOP after phaco-KDB and external phaco-trabeculotomy was 16.1 and 15.9 $\mathrm{mmHg}$, respectively. There was a significant turn back elevation of once reduced IOP to 17.1 $(P=0.0207)$ and $17.0 \mathrm{mmHg}(P=0.0096)$ at 24 months, respectively. There were no differences in success probability to achieve IOP below $17 \mathrm{mmHg}(P=0.120), 21 \mathrm{mmHg}$ $(P=0.719)$ and $>20 \%$ IOP reduction $(P=0.309)$ with medication(s) at two years between the phaco-KDB and external phaco-trabeculotomy cohorts. Younger age was a significant $(P<0.001)$ risk factor for failure; however, presurgical IOP $(P=0.466)$, the type of surgery $(P=0.219)$ and presence of postsurgical IOP spike $(P=0.737)$ were not significant risk factors by the Cox proportional hazard model. Hyphema and spike of the IOP in phacoKDB and external phaco-trabeculotomy cohorts were $40 \%$ and $88 \%(P<0.001)$, and $53 \%$ and $41 \%(P=0.238)$, respectively.

Conclusion: The IOP reduction by the phaco-KDB was equivalent to that by external phaco-trabeculotomy up to two years. In both cohorts, once reduced postsurgical IOP tend to increase up to 24 months.

Keywords: MIGS, external trabeculotomy, Kahook dual blade, spike of IOP, Schlemm's canal surgery

\section{Introduction}

In recent days, application of the internal canal surgery (minimally invasive Schlemm's canal surgery; MISCS) is increasing in number as one of the minimally invasive glaucoma surgeries (MIGS). Trabectome, ${ }^{1}$ iStent, $^{2}$ gonioscopy-assisted transluminal trabeculotomy, ${ }^{3} 360$ degree suture trabeculotomy, ${ }^{4}$ Kahook dual blade (KDB), ${ }^{5}$ Tanito micro hook ${ }^{6}$ and internal canaloplasty ${ }^{7}$ have all been reported as ab interno techniques, which are nontraumatic to conjunctiva, less time
Correspondence: Etsuo Chihara

Sensho-Kai Eye Institute, Minamiyama 50

I, Iseda, Uji, Kyoto 6I I-0043, Japan

Tel +8I-774-45-2060

Fax +8I-774-45-4565

Email chiha49200I@gmail.com 
consuming, and have lower chances of complications than external trabeculotomy or trabeculectomy., ${ }^{5,8}$ Because of these factors, internal canal surgery is increasingly employed in the world. ${ }^{9}$

The basic pressure lowering mechanism, that is to open the Schlemm's canal, may be the same between MISCS and the external trabeculotomy. Thus, clinical characteristics of the external trabeculotomy such as high efficacy to treat adult onset primary open angle glaucoma (POAG), ${ }^{10}$ developmental glaucoma, ${ }^{11}$ steroid induced glaucoma, ${ }^{12,13}$ glaucoma in old patients, ${ }^{14}$ and pseudoexfoliation glaucoma $(\mathrm{PEG})^{15}$ may be shared with MISCS. Characteristics of the external trabeculotomy such as low efficacy to achieve low teen intraocular pressure, ${ }^{16}$ and low success provability in patients with postoperative spikes of the intraocular pressure (IOP) and those with high preoperative $\mathrm{IOP}^{14}$ may also be shared with MISCS. However, there may be differences in the surgical wound between the MISCS and external trabeculotomy.

One of the worrisome issues concerning the surgical outcome of the MISCS is a re-elevation of once reduced IOP. Regeneration of destroyed trabecular meshwork or increase of the outflow resistance at the intrascleral collector channel may occur and a turn back elevation of the once reduced IOP may occur in phaco-KDB cases. In this study, we compared the surgical outcome of the phacoKDB and external phaco-trabeculotomy cases, studied prevalence of postsurgical spike of IOP and hyphema and studied postsurgical re-elevation of the IOP.

\section{Patients and Methods}

This is a retrospective comparative study. The study design was approved by an institutional review board of the Sensho-kai (Head, Mr Amano: approved as 2018-\#8 on 2018/12/3) and informed consent concerning data acquisition was obtained at the time of surgery from all patients. The study design complied with the tenet of the Declaration of the Helsinki.

Inclusion criteria for the study included diagnosis of primary open angle glaucoma (POAG), pseudoexfoliation glaucoma (PEG), and ocular hypertension $(\mathrm{OH})$ in patients aged 40 years or older, combined with a clinically significant cataract and indicated for surgical intervention because of high IOP or progression of the visual field defects. OH patients had a history of high IOP of $21 \mathrm{mmHg}$ or greater and open angle without any glaucomatous optic neuropathy. POAG and PEG patients had glaucomatous optic neuropathy, open angle, and mild to moderate glaucomatous visual field defects. These patients had baseline presurgical IOPs between $18 \mathrm{mmHg}$ and 39 $\mathrm{mmHg}$, underwent external phaco-trabeculotomy or phaco-KDB surgery, which was performed by one surgeon (EC) at the Sensho-kai Eye Institute and underwent follow-up for more than six months. In this study, the presurgical IOP was measured before prescription of eye drops or after washout of previously prescribed medicines, and this presurgical IOP without medication was set as a baseline IOP. Exclusion criteria included secondary glaucoma except for PEG, eyes complicated with intraoperative posterior capsular damage and/or vitreous loss, developmental glaucoma, primary angle closure glaucoma (PACG), and normal tension glaucoma (NTG). Patients with neuro-ophthalmological disease, uveitis, congenital disease, vascular disease, a history of trauma, corneal diseases and proliferative vitreo-retinal diseases also were excluded. No patients had a history of previous interventional surgery.

Before 2016, the surgical procedure selected was external phaco-trabeculotomy. After introduction of MISCS in 2016, phaco-KDB was the selected procedure instead. Visual field defects were studied utilizing the Humphrey Visual Field Analyzer (Carl Zeiss Meditec, Tokyo, Japan), and visual acuity was measured utilizing a CV 500 visual acuity tester (Takagi Co. Nagano, Japan).

In this study, one eye each of 40 phaco-KDB treated patients (25 POAG, $8 \mathrm{PEG}$, and $7 \mathrm{OH}$ ) who met the enrollment criteria were selected from 80 eyes of 73 patients who underwent phaco-KDB between November 2016 and March 2020. If both eyes were eligible, the eye with the higher baseline IOP was selected for study inclusion. Based on the same criteria, one eye each from 76 patients (48 POAG, 13 PEG, and $15 \mathrm{OH}$ ) was selected from 153 eyes of 118 patients who underwent external phaco-trabeculotomy at the same institute before 2016. These eyes served as a control.

The primary outcome measured in this study was the postsurgical IOP, measured by Goldmann applanation tonometer. Postsurgical hyphema was studied as a secondary outcome measure.

After the surgery, spike of IOP and hyphema was examined for a week and if necessary, antiglaucoma regimens were used to control the spike. Postsurgical shortterm IOP elevation until two months after surgery was not counted as failure. The postsurgical IOP were studied at one week, one month, and three months, and thereafter the 
time schedule to measure the IOP was every three months after surgery.

Three criteria for success were set for cumulative surviving proportion (Kaplan-Meier) analysis. These criteria were IOP below $21 \mathrm{mmHg}$, below $17 \mathrm{mmHg}$, and IOP reduction of $20 \%$ or more of the baseline with or without medications at two consecutive visits after three months postsurgery without any additional glaucoma surgery. Log rank test was performed to assess difference between the two cohorts within 24 months. Mann-Whitney $U$-test was used to compare the IOP at one week, one, three, six, 12, 18 , and 24 months postsurgery between the external phaco-trabeculotomy and phaco-KDB cohorts. Comparison between baseline IOP and IOP at one week, one, three, six, 12, 18 and 24 months postsurgery was analyzed by a Wilcoxon signed rank test. Turn back elevation of the IOP was assessed by comparing the IOP at three months with those at 18 months and 24 months. The Cox proportional hazard model was used to assess risk factors that affect the success probability to achieve 17 $\mathrm{mmHg}$ under medication.

The correlation between magnitude of IOP reduction and presurgical IOP was assessed by Spearman's rank correlation coefficient.

Postoperative hyphema was defined as blood pooling $1 \mathrm{~mm}$ or higher in the anterior chamber. Postoperative IOP spike was defined as an increase of IOP by $5 \mathrm{mmHg}$ or more relative to the baseline IOP. Differences in the occurrence of hyphema and IOP spikes between the cohorts was assessed by Fisher's exact test. Results were considered significant with a $P<0.05$.

\section{Surgical Procedures of the External Trabeculotomy and KDB Surgery Combined with Cataract Surgery}

As a first step of external phaco-trabeculotomy, cataract surgery was performed as a first step, and trabeculotomy procedures followed techniques described previously. ${ }^{17}$ A metal trabeculotomy probe (Inami Co., Tokyo, Japan) was inserted into the Schlemm's canal and in-rotated to disrupt the inner wall of the Schlemm's canal at superior 120 circumferential degrees. Thereafter the scleral flap was secured to be watertight by five $10-0$ nylons. Postsurgically, topical pilocarpine was applied for two weeks. Topical steroids $(0.1 \%$ betamethasone $)$ and antibiotics (ofloxacin) were administered four times per day for four weeks.
In the case of phaco-KDB, a corneal incision and creation of the continuous curvilinear capsulorhexis were the first step, that was followed by injection of viscoelastic material. Then, 120 to 150 degrees of the inferior trabecular meshwork was excised using a KDB (Japan Focus Ltd, Tokyo, Japan) under direct observation of the angle using a Hill's Gonio lens (Ocular, RE Medical, Tokyo, Japan). The excised trabecular strip was removed by Gaskin's forceps (Inami Co.), after which the eyes underwent phaco-lensectomy and IOL implantation, and irrigation by $400 \dot{x}$ acetyl choline solution to induce miosis. Postsurgically, topical pilocarpine was applied for two weeks. Topical antibiotics (ofloxacin or gatifloxacin) and $0.1 \%$ betamethasone were used for four weeks after the KDB surgery.

\section{Results}

Demographic presurgery data for each cohort is listed in Table 1. There was no difference in age, refractive error, visual field defects, presurgical baseline IOP without mediation, however, cataracts were more significant in the external trabeculotomy cohort, and baseline visual acuity and number of topical medications of the external phacotrabeculotomy cohort was inferior to that of phaco-KDB cohorts. Mean follow-up period for phaco-KDB and external phaco-trabeculotomy were $18.2 \pm 10.1$ and $41.4 \pm 38.4$ months, respectively. Difference in type of glaucoma between the two cohorts assessed by chi-squared test was not significant by $\mathrm{p}=0.968$.

The baseline IOP without medication in phaco-KDB and external phaco-trabeculotomy cohorts were $24.0 \pm 4.3$ and $25.1 \pm 4.1 \mathrm{mmHg}$, which lowered to $17.2 \pm 2.5$ (28.4 $\pm 15.7 \%$ reduction) and $16.5 \pm 2.6(32.7 \pm 14.5 \%$ reduction; $P=0.256$ by Mann-Whitney $U$-test) at one year, and $17.1 \pm 2.8 \quad(27.8 \pm 11.5 \%$ reduction $)$ and $17.3 .0 \pm 3.3$ mmHg $(31.5 \pm 18.6 \%$ reduction; $P=0.468$ by MannWhitney $U$-test) at two years, respectively (Table 2). There was no statistical difference by Mann-Whitney $U$-test in presurgical IOP $(P=0.147)$, postsurgical IOP at 12 months $(P=0.245)$, and 24 months $(P=0.608)$ between the two cohorts (Table 2).

The presurgical baseline IOPs of $24.0 \pm 4.3$, and 25.1 $\pm 4.1 \mathrm{mmHg}$ in phaco-KDB and external phacotrabeculotomy cohorts were significantly lowered at one, three, six, 12, 18, and 24 months as assessed by the Wilcoxon signed rank test. (Figure 1 and Table 2). The postsurgical IOP at one week after phaco-KDB surgery, 
Table I Baseline Data for Phaco-KDB and External Phaco-Trabeculotomy Cohorts

\begin{tabular}{|c|c|c|c|c|c|c|}
\hline & $\begin{array}{l}\text { Age } \\
\text { (years) }\end{array}$ & $\begin{array}{l}\text { Preoperative BCVA } \\
\text { Log MAR }\end{array}$ & $\begin{array}{l}\text { Preoperative Ref } \\
\text { Error (D) }\end{array}$ & $\begin{array}{l}\text { Preoperative } \\
M D(d B)^{a}\end{array}$ & $\begin{array}{l}\text { Baseline } \\
\text { IOP }\end{array}$ & $\begin{array}{l}\text { Preoperative } \\
\text { Meds }\end{array}$ \\
\hline Phaco-KDB N & 40 & 40 & 40 & 39 & 40 & 40 \\
\hline Mean \pm SD & $\begin{array}{l}73.9 \pm 8.1 \\
(56-88)\end{array}$ & $\begin{array}{l}0.185 \pm 0.301 \\
(-0.18-1.52)\end{array}$ & $\begin{array}{l}-2.72 \pm 4.82 \\
(-18.4-5.12)\end{array}$ & $\begin{array}{l}-8.46 \pm 7.93 \\
(-19.8-0.09)\end{array}$ & $\begin{array}{l}24.0 \pm 4.3 \\
(18-39)\end{array}$ & $2.4 \pm 1.4(0-5)$ \\
\hline $\begin{array}{l}\text { External phaco- } \\
\text { trabeculotomy } \mathrm{N}\end{array}$ & 76 & 74 & 72 & 30 & 76 & 76 \\
\hline Mean \pm SD & $\begin{array}{l}72.2 \pm 9.5 \\
(48-93)\end{array}$ & $\begin{array}{l}0.468 \pm 0.473 \\
(-0.08-2.0)\end{array}$ & $\begin{array}{l}-2.59 \pm 5.68(-22- \\
4.5)\end{array}$ & $\begin{array}{l}-7.94 \pm 6.78 \\
(-18.0-0.2)\end{array}$ & $\begin{array}{l}25.1 \pm 4.1 \\
(18-37)\end{array}$ & $1.7 \pm 0.9(0-4)$ \\
\hline $\begin{array}{l}\text { Mann-Whitney } \\
U \text { P-value }\end{array}$ & 0.380 & $<0.001$ & 0.448 & 0.947 & 0.147 & 0.008 \\
\hline
\end{tabular}

Notes: A range was shown in brackets. ${ }^{a}$ Visual fields data studied by kinetic perimeter were deleted.

Abbreviations: BCVA, best corrected visual acuity; logMAR, logarithmic minimum angle of resolution; D, diopters; dB, decibels; IOP, intraocular pressure; Baseline IOP, pre-surgical IOP without medication; meds, medication(s); Phaco, phacoemulsification aspiration and implantation of intraocular lens; KDB, Kahook dual blade surgery.

Table 2 Time Course of IOP, Comparison Between Phaco-KDB and External Phaco-trabeculotomy Cohorts by Mann-Whitney U-test and Postsurgical Reduction of IOP Against Baseline IOP and IOP at Three Months Evaluated by Wilcoxon Signed Rank Test

\begin{tabular}{|c|c|c|c|c|c|c|c|c|}
\hline & $\begin{array}{l}\text { Baseline } \\
\text { IOP }\end{array}$ & $\begin{array}{l}\text { I } \\
\text { Week }\end{array}$ & $\begin{array}{l}\text { I } \\
\text { Month }\end{array}$ & $\begin{array}{l}3 \\
\text { Months }\end{array}$ & $\begin{array}{l}6 \\
\text { Months }\end{array}$ & $12 \mathrm{M}$ & $18 M$ & 24M \\
\hline Phaco-KDB N & 40 & 40 & 40 & 40 & 39 & 27 & 19 & 13 \\
\hline Phaco-KDB (mmHg) & $24.0 \pm 4.3$ & $23.4 \pm 9.8$ & $16.2 \pm 3.5$ & $16.1 \pm 4.5$ & $15.2 \pm 2.7$ & $17.2 \pm 2.5$ & $16.5 \pm 2.1$ & $17.1 \pm 2.8$ \\
\hline Wilcoxon ${ }^{\text {a }} P$-value evaluated against baseline IOP & & 0.464 & $<0.001$ & $<0.001$ & $<0.001$ & $<0.001$ & $<0.001$ & 0.0015 \\
\hline Wilcoxon ${ }^{\text {a }} P$-value evaluated against IOP at 3 months & & & & & $P=0.175$ & $P=0.003$ & $\mathrm{P}=0.0255$ & $\mathrm{P}=0.0207$ \\
\hline External phaco-trabeculotomy $\mathrm{N}$ & 76 & 71 & 76 & 75 & 70 & 63 & 55 & 53 \\
\hline External phaco-trabeculotomy $(\mathrm{mmHg})$ & $25.1 \pm 4.1$ & $18.6 \pm 6.8$ & $16.0 \pm 3.4$ & $15.9 \pm 3.4$ & $16.6 \pm 3.5$ & $16.5 \pm 2.6$ & $16.9 \pm 2.6$ & $17.0 \pm 3.3$ \\
\hline Wilcoxon ${ }^{\text {a }} P$-value evaluated against baseline IOP & & $<0.001$ & $<0.001$ & $<0.001$ & $<0.001$ & $<0.001$ & $<0.001$ & $\mathrm{P}<0.001$ \\
\hline Wilcoxon ${ }^{\text {a }} P$-value evaluated against IOP at 3 months & & & & & $P=0.446$ & $P=0.1213$ & $P=0.0042$ & $P=0.0096$ \\
\hline $\begin{array}{l}\text { Mann-Whitney U-test }{ }^{\mathrm{b}} P \text {-value between phaco-KDB } \\
\text { and external phaco-trabeculotomy }\end{array}$ & 0.147 & $0.017 *$ & 0.659 & 0.752 & $0.034^{*}$ & 0.245 & 0.481 & 0.608 \\
\hline
\end{tabular}

Notes: Patients were followed for more than six months, however, data was blank when they did not visit. ${ }^{a}$ Wilcoxon signed rank test. ${ }^{\mathrm{b}}$ Mann-Whitney $U$-test. $*$ Significant by $P<0.05$.

Abbreviations: IOP, intraocular pressure; Baseline IOP, presurgical IOP without medication; Phaco, phacoemulsification aspiration and implantation of intraocular lens; KDB, Kahook dual blade surgery.

which was $23.4 \pm 9.8$, was higher than the IOP of 18.6 $\pm 6.8 \mathrm{mmHg}$ after external phaco-trabeculotomy $(P=0.017$ by Mann-Whitney $U$-test, Table 2).

Difference in postsurgical IOPs between phaco-KDB and external phaco-trabeculotomy cohorts were not significant at one month $(P=0.659)$, three months $(\mathrm{p}=0.752), 12$ months $(P=0.245), 18$ months $(P=0.481)$ and 24 months $(P=0.608)$ by the Mann-Whitney $U$-test, however small difference was found at six months $(P=0.034)$ (Table 2$)$. The lowest IOP after the external phaco-trabeculotomy and phaco-KDB was observed at three months and six months, respectively. After that, there was a mild but significant turn back elevation of the IOP in both cohorts. The IOP at 18 and 24 months were significantly higher than that of three months by $P=0.0255$ and 0.0207 for phaco-KDB, and $P=0.0042$ and 0.0096 for external phaco-trabeculotomy eyes (Wilcoxon signed rank test), respectively (Table 2). Number of medications before surgery in phaco-KDB and external phaco-trabeculotomy cohorts were $2.4 \pm 1.4$ and $1.7 \pm 0.9$, which decreased at three, 12 , and 24 months after phaco-KDB and external phacotrabeculotomy to $1.1 \pm 1.0 \quad(P<0.001$ Wilcoxon signed rank test), $1.0 \pm 1.1(P<0.001)$ and $1.0 \pm 0.9(P=0.0207)$, and $0.5 \pm 0.7(P<0.001), 0.7 \pm 0.9(P<0.001)$ and $0.8 \pm 0.9$ $(P<0.001)$, respectively. When the rate of IOP reduction 


\section{Time course of IOP reduction}

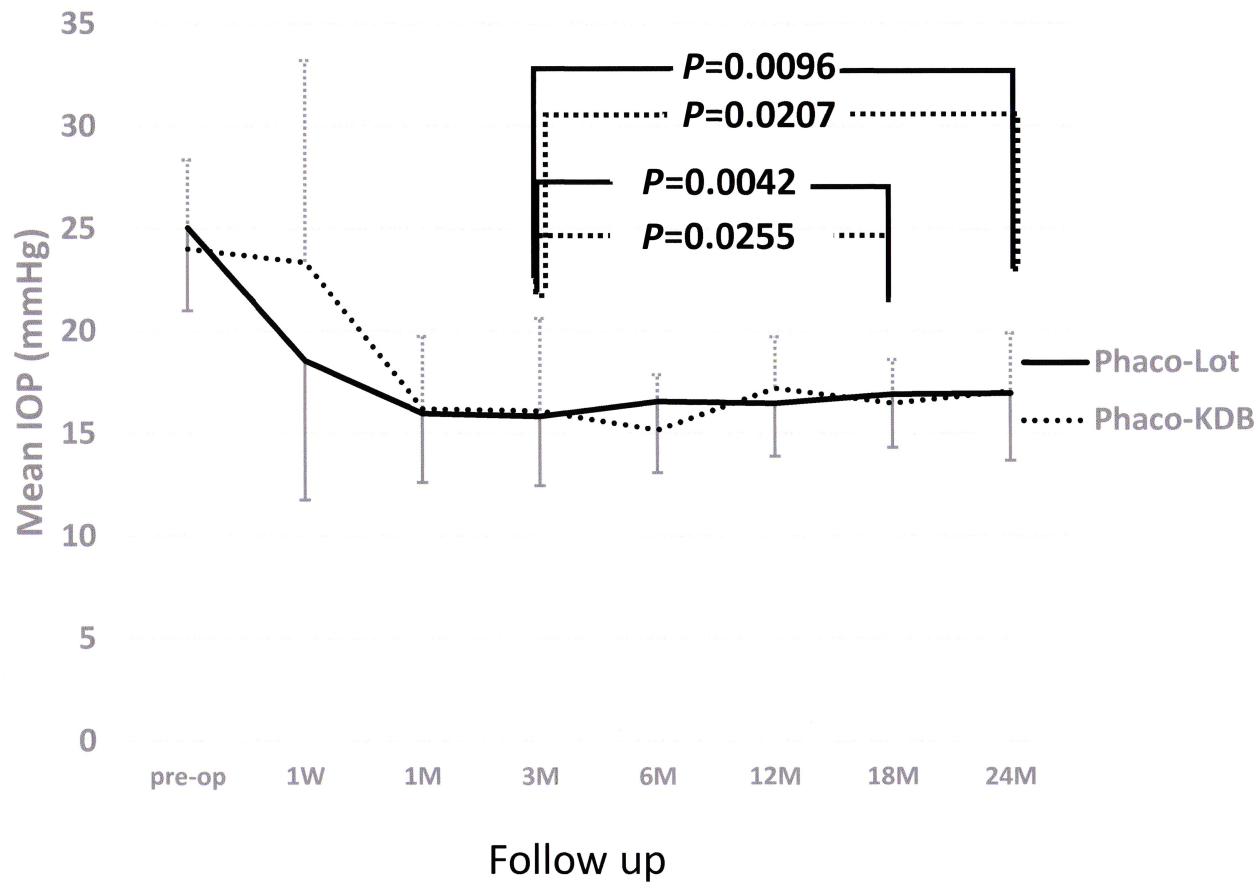

Figure I Pre- and postsurgical intraocular pressure after external phaco-trabeculotomy and phaco-KDB surgeries. There was a statistically significant IOP reduction from the baseline in both cohorts by Wilcoxon signed rank test. Postsurgical IOP at one week was higher in the phaco-KDB than external phaco-trabeculotomy (Phaco-Lot) eyes by the Mann-Whitney $U$-test $(P=0.017)$. The lowest postsurgical IOP was recoded at three to six months, thereafter mild but statistically significant turn back elevation of IOP was recoded. The IOP at 18 months and 24 months were significantly higher than that at three months in each cohort ( $P$ by Wilcoxon signed rank test; Table 2 ).

at six and 12 months was compared with the baseline IOP by Spearman's rank correlation coefficient, the efficiency to reduce IOP was high when the baseline IOP was high in both the phaco-KDB and external phacotrabeculotomy (Tables 3 and 4). The correlation coefficient between the baseline IOP and rate of IOP reduction at six and 12 months was significant by $P<0.001$ in both the phaco-KDB and external phacotrabeculotomy cases. While association between presurgical baseline IOP and postsurgical IOP at 12 months was not significant, that was $P=0.518$ for phaco-KDB cases and $P=0.700$ for external phaco-trabeculotomy cases (Tables 3 and 4).

Cumulative surviving proportion (Kaplan-Meier) analysis to achieve IOP $<17 \mathrm{mmHg}$, IOP $<21 \mathrm{mmHg}$, and $>20 \%$ IOP reduction with medication in each cohort is shown in Figure $2 \mathrm{~A}-\mathrm{C}$. The success probability to achieve IOP $<17 \mathrm{mmHg}$, and $<21 \mathrm{mmHg},>20 \%$ IOP reduction at one year in phaco-KDB and external phacotrabeculotomy cohort were $0.702 \pm 0.077$ and 0.572 $\pm 0.059, \quad 0.895 \pm 0.050$ and $0.944 \pm 0.027$, and 0.773 \pm 0.067 and $0.780 \pm 0.048$, respectively. The success

Table 3 Matrix Table of Spearman's Rank Correlation Coefficient Between Baseline IOP, Rate of Postsurgical IOP Reduction and IOP at Six and 12 Months in Phaco-KDB Eyes

\begin{tabular}{|c|c|c|c|c|c|}
\hline & $\begin{array}{l}\text { Baseline } \\
\text { IOP }\end{array}$ & $\begin{array}{l}\text { IOP at } 6 \\
\text { months }\end{array}$ & $\begin{array}{l}\text { \% IOP Reduction } 6 \\
\text { months }\end{array}$ & $\begin{array}{l}\text { IOP at } 12 \\
\text { months }\end{array}$ & $\begin{array}{l}\% \text { IOP Reduction } 12 \\
\text { months }\end{array}$ \\
\hline Baseline IOP & - & 0.908 & $<0.001$ & 0.518 & $<0.001$ \\
\hline IOP at $6 \mathrm{M}$ & & - & $<0.001$ & 0.026 & 0.163 \\
\hline$\%$ IOP reduction $6 \mathrm{M}$ & $* *$ & $* *$ & - & 0.042 & $<0.001$ \\
\hline IOP at $12 \mathrm{M}$ & & $*$ & $*$ & - & $<0.001$ \\
\hline$\%$ IOP reduction $12 \mathrm{M}$ & $* *$ & & $* *$ & $* *$ & - \\
\hline
\end{tabular}

Notes: Baseline IOP is a presurgical IOP measurements without medication. *Significant by $P<0.05$. **Significant by $P<0.01$. 
Table 4 Matrix Table of Spearman's Rank Correlation Coefficient Between Baseline IOP, Rate of Postsurgical IOP Reduction and IOP at Six and 12 Months in External Phaco-Trabeculotomy Eyes

\begin{tabular}{|l|l|l|l|l|l|}
\hline & $\begin{array}{l}\text { Baseline } \\
\text { IOP }\end{array}$ & $\begin{array}{l}\text { IOP at 6 } \\
\text { months }\end{array}$ & $\begin{array}{l}\text { \% IOP Reduction 6 } \\
\text { months }\end{array}$ & $\begin{array}{l}\text { IOP at I2 } \\
\text { months }\end{array}$ & $\begin{array}{l}\text { \% IOP Reduction I2 } \\
\text { months }\end{array}$ \\
\hline Baseline IOP & - & 0.623 & $<0.001$ & 0.700 & $<0.00$ I \\
IOP at 6 months & & - & $<0.001$ & 0.274 & 0.515 \\
\% IOP reduction 6 months & $* *$ & $* *$ & - & 0.435 & $<0.001$ \\
IOP at I2 months & & & $* *$ & $* *$ & $<0.001$ \\
\% IOP reduction 12 months & $* *$ & & & - & - \\
\hline
\end{tabular}

Notes: Baseline IOP is a presurgical IOP without medication. *Significant by $P<0.05$. **Significant by $P<0.0$ I.

probability in phaco-KDB and external phacotrabeculotomy cohort and log rank test $P$-value at two years were $0.606 \pm 0.093$ and $0.472 \pm 0.061$
$(P=0.120), \quad 0.895 \pm 0.050$ and $0.910 \pm 0.035 \quad(P=0.719)$, and $0.565 \pm 0.094$ and $0.682 \pm 0.057(P=0.309)$, respectively (Figure 2). There was no difference in the success
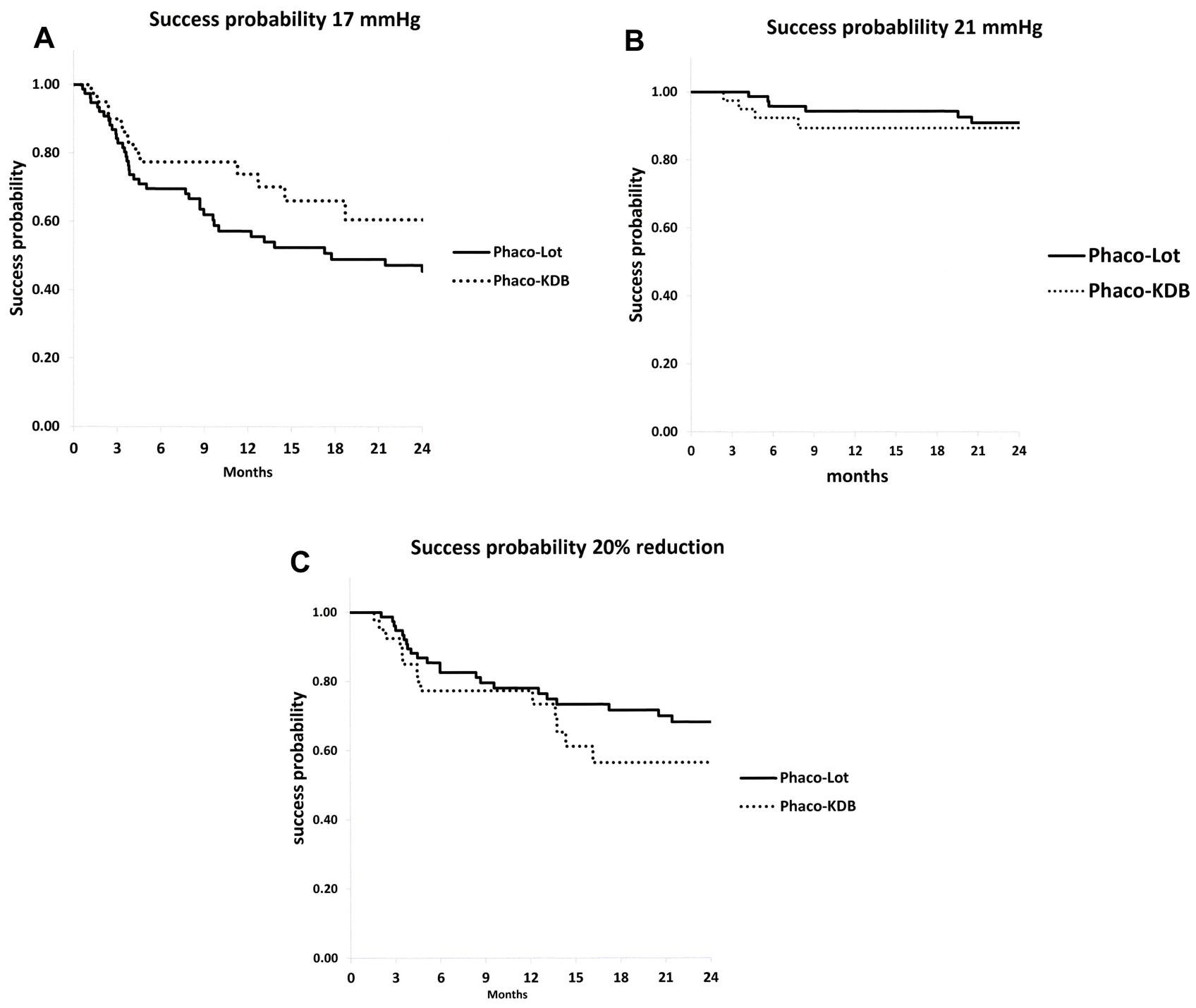

Figure 2 (A-C) Cumulative surviving proportion (Kaplan-Meier) analysis to achieve three success criteria by the phaco-KDB and external phaco-trabeculotomy (PhacoLot) procedures: (A) Success probability to achieve IOP $<17 \mathrm{mmHg}$ with medication, (B) Success probability to achieve IOP $<21 \mathrm{mmHg}$ with medication, and (C) Success probability to achieve $>20 \%$ IOP reduction with medication. By the log rank test, there was no statistical significance in the success probability to achieve $<17 \mathrm{mmHg}$ $(P=0.120),<21 \mathrm{mmHg}(P=0.719)$ and $>20 \%$ IOP reduction $(P=0.309)$ between the two cohorts. 
Table 5 Risk Factors Assessed by Cox Proportional Hazard Ratio to Achieve $17 \mathrm{mmHg}$ Under Medication

\begin{tabular}{|l|l|l|l|l|l|}
\hline Risk Factor & $\chi^{2}$ & $P$ & Hazard Ratio (Exp) & Inferior Limit & Superior Limit \\
\hline Age & 13.01 & $<0.001^{*}$ & 0.936 & 0.903 & 0.970 \\
Refractive error & 1.045 & 0.307 & 1.028 & 0.975 & 1.085 \\
Baseline IOP & 0.531 & 0.466 & 1.021 & 0.965 & 1.081 \\
Procedures (KDB or LOT) & 1.511 & 0.219 & 0.660 & 0.340 & 1.280 \\
Spike Yes/No & 0.113 & 0.737 & 1.099 & 0.634 & 1.905 \\
\hline
\end{tabular}

Notes: Baseline IOP is a presurgical IOP without medication. *Statistically significant.

Abbreviations: IOP, intraocular pressure; KDB, Kahook dual blade surgery; LOT, external trabeculotomy surgery.

probability between the two cohorts for any of the three measures.

Postsurgical hyphema was found in 67 of 76 eyes (88\%) after external phaco-trabeculotomy, this prevalence was higher than that within phaco-KDB cohort in which 16 of 40 eyes $(40 \%)$ had hyphema $(P<0.001$, Fisher's exact test). In contrast to the high prevalence of the hyphema in external phaco-trabeculotomy cohort, the prevalence of IOP spike after phaco-KDB (21 of 40 eyes, $53 \%$ ) did not differ significantly from that after external phaco-trabeculotomy ( 30 of 76 eyes, $41 \%$; $P=0.238$ by Fisher's exact test). Also there was no difference between the height of IOP spike after phaco-KDB (38.0 \pm 10.1 $\mathrm{mmHg}$ ) and external phaco-trabeculotomy

$(35.3$ $\pm 8.9 \mathrm{mmHg} ; P=0.415$ by Mann-Whitney $U$-test).

Risk factors for failure to achieve IOP $<17 \mathrm{mmHg}$ with medication was analyzed using the Cox proportional hazard model (Table 5). Younger age was a significant risk factor for failure with $P<0.001$ (Table 5). While, a refractive error $(P=0.307)$, a high presurgical IOP $(P=0.466)$, the type of surgery $(P=0.219)$ and presence of a postsurgical spike $(P=0.737)$ were not risk factors to achieve IOP criteria of $17 \mathrm{mmHg}$ (Table 5).

\section{Discussion}

Removal of the outflow resistance at the trabecular meshwork will lead to reduction of the IOP. However, one of the concerns is a mild but significant turn back elevation of the IOP after that. Mechanism of the turn back elevation of the IOP after MISCS may differ from that after the filtering surgery. There may be two mechanisms for an increase in the outflow resistance; one is healing processes at the trabecular meshwork and the other is damage in the intrascleral collector channel. Regeneration and scaring of the angle tissue in both techniques may progress over years, and lead to higher IOP at 18 and 24 months than those at three months in both the phaco-KDB and external phaco-trabeculotomy cohorts. In previous reports, re-elevation of $\mathrm{IOP}^{18}$ or increase in number of postsurgical medications after the canal surgery ${ }^{17}$ had been suggested without scientific analysis for the reasons.

In the case of trabeculotomy, the trabecular meshwork is opened like a single or double door by blunt trauma from the metal probe. This differs from KDB, in which the trabecular meshwork is internally excised by a knife. In case of trabeculotomy, postsurgical fusion of residual trabecular meshwork leaflets may lead to regeneration of the trabecular meshwork and subsequently may hamper aqueous outflow. In previous studies, Dannheim et al and Ito et al reported that the histopathological canal opening by trabeculotomy was closed by granular tissue within four months after surgery. ${ }^{19,20}$ In case of KDB, meshwork tissue is removed, and trabecular septa ${ }^{21}$ may also be destroyed by the double blade, while excision of the meshwork by the KDB may lead to long-lasting opening of the canal. In spite of these differences, IOP reduction in the two cohorts and the success probability to achieve 17, 21 $\mathrm{mmHg}$ and $20 \%$ IOP reduction by the cumulative surviving proportion (Kaplan-Meier) analysis were equivalent. Another factor which may affect the outcome is the meridian of the excised meshwork. In this study the Schlemm canal opening by the external trabeculotomy was confined to the superior half of the eye, while the opening by KDB was confined to the inferior half. If the efficiency to drain aqueous was higher at inferonasal part of the collector channel, $^{22}$ greater IOP reduction may be expected in KDB cases. While disadvantage of inferior canal opening may be clogging of inferior collector channels, which may counteract strength of the KDB. Postsurgical blood coagula sink with gravity and may lead to obstruction of the inferior collector channel.

In this study, older age was a positive factor to reduce surgical IOP (Table 5). Association between age of patients and surgical outcome had been studied previously, ${ }^{23}$ and our finding is concordant with the results of a previous report. ${ }^{14}$ If the endothelium of the 
Schlemm's canal decreases with age, ${ }^{24}$ and repair of damaged endothelial lining is poor in older patients, the canal opening may remain long and lead to good control of IOP in old patients.

Other than the healing processes at the trabecular meshwork, increase in the intrascleral outflow resistance may also participate in gradual increase in postsurgical IOP. Postsurgical IOPs were in the high teens for both types of canal surgeries. Even though Mäepea and Bill reported low intrascleral resistance of aqueous outflow, ${ }^{25}$ the reduction in outflow resistance of cadaver eyes after complete removal of the trabecular meshwork is no more than $71 \%$, which suggests the presence of intrascleral outflow resistance. ${ }^{26}$ Integrity of the collector channel is guarded by the trabecular meshwork which scavenge cell debris in the aqueous and blocks accumulation of extracellular materials at the collector channel. ${ }^{27}$ When the collector channel connects directly with anterior chamber without any protection by the trabecular meshwork, cellular debris may flow into the collector channel and the intrascleral outflow resistance may increase over time.

We observed many cases with postoperative short-term hyphema in both cohorts, which could potentially clog the outlet and spike the IOP. Concerning the short-term complications after surgery, one of the differences between two cohorts was a higher prevalence of hyphema in external phaco-trabeculotomy patients and the other difference is higher IOP in phaco-KDB patients one week after the surgery. In case of external phaco-trabeculotomy, the surgical wound of a $4 \dot{\times} 4 \mathrm{~mm}$ scleral flap is greater than that created by KDB and may cause a greater risk of bleeding and wound leakage that counterbalance spike of IOP. It is plausible that postsurgical hyphema caused short-term higher IOP after watertight KDB surgery than the IOP after external trabeculotomy, which has a large and leaky scleral wound. In a previous report, effects of hyphema on long-term outcome of the canal surgery had been of concern. ${ }^{14}$ Bleeding associated fibrin reaction may cause obstruction of the collector channel and increase in the IOP. However, the postsurgical IOP in this study was not affected by the spike as analyzed by the Cox proportional hazard ratio model (Table 5). As was reported previously, $^{28}$ effects of postsurgical hyphema and IOP spike may be short and only a minor factor on the final surgical outcome.

In this report, higher presurgical IOP was associated with greater IOP reduction in both the phaco-KDB and external phaco-trabeculotomy cohorts (Tables 3 and 4). In a previous study an increase of $1 \mathrm{mmHg}$ in baseline IOP correlated to an additional IOP reduction of $0.80 \pm 0.02$ $\mathrm{mmHg}$ in the trabectome cases. ${ }^{29}$ Higher presurgical IOP is associated with a larger IOP reduction in the KDB cases $^{30}$ and iStent cases. ${ }^{31}$ These characteristics are in accordance with previous results of the external trabeculotomy study. ${ }^{32}$ If the pathogenesis of IOP elevation was attributed to increased resistance at the trabecular meshwork, it is reasonable that magnitude of IOP reduction by the canal opening is proportional to the height of presurgical IOP. However, there are some reports concerning positive association between presurgical IOP level and postsurgical IOP level. ${ }^{14}$ Eyes with high presurgical IOP may have higher outflow resistance at the intrascleral route and a risk of higher postsurgical IOP. So far as the current study is concerned, patients with high presurgical IOP were excluded by the inclusion criteria. This bias may be the reason why presurgical high IOP was not included in the risk factors for failure by the Cox proportional hazard model.

\section{Conclusion}

In conclusion, difference in surgical outcomes between external phaco-trabeculotomy and phaco-MISCS was small in this study. The surgical procedure of the external phaco-trabeculotomy is time consuming, has a high risk of hyphema, and has a turn back elevation of postsurgical IOP. Because of its simplicity in technique, phaco-MISCS may replace old type canal surgery. However, we must be careful that effects of the phaco-KDB may wane over time. If the postsurgical IOP elevates over time, strengthening of antiglaucoma treatment may be required after the MISCS.

\section{Limitation of This Study}

Number of antiglaucoma medications may affect the outcome. The optimal situation to assess the effects of surgery is comparing the pre- and postsurgical IOP precisely under the same medications. In this study, baseline IOP was the measure without medication, while 0.5 to 1.1 antiglaucoma medications were used after the surgery. Use of eye drops might have affected postsurgical evaluation of the IOP. However, both the postsurgical medication(s) and IOP are increasing, the elevation of postsurgical IOP cannot be attributed to number of medications. In this study, follow-up time in some patients was short and reduction in number of patients to 13 at 24 months after phaco-KDB may be concerned. However, the trends of IOP measure in eyes which 
were followed for 24 months was quite similar to the trends in eyes which were followed for 12 months. Therefore, statistical evaluation of 24 months data by 13 samples may not be so reckless. In this study, surgical procedures were converted in 2016, and this difference in time might have affected the results. The number of subjects in phaco-KDB was small in comparison to that in external phaco-trabeculotomy cohort. Future prospective, randomized control study on a large sample size will improve consistency of results.

\section{Acknowledgments}

We have not received any financial support from the industry or government. A part of this report was presented on April 18, 2019 at the Japanese Ophthalmological Society meeting in Tokyo. We are thankful to Dr K Hayashi for her help to collect data.

\section{Disclosure}

The authors report no conflict of interest in this work.

\section{References}

1. Minckler DS, Baerveldt G, Alfaro MR, et al. Clinical results with the trabectome for treatment of open-angle glaucoma. Ophthalmology. 2005;112:962-967.

2. Spiegel D, Wetzel W, Haffner DS, et al. Initial clinical experience with the trabecular micro-bypass stent in patients with glaucoma. $A d v$ Ther. 2007;24(1):161-170. doi:10.1007/BF02850004

3. Grover DS, Godfrey DG, Smith O, et al. Gonioscopy-assisted transluminal trabeculotomy, ab interno trabeculotomy: technique report and preliminary results. Ophthalmology. 2014;121(4):855-861. doi:10.1016/j.ophtha.2013.11.001

4. Chin S, Nitta T, Shinmei Y, et al. Reduction of intraocular pressure using modified 360-degree suture trabeculotomy technique in primary and secondary open-angle glaucoma: a pilot study J Glaucoma. 2012;21:401-407. doi:10.1097/IJG.0b013e318218240c

5. Seibold LK, Soohoo JR, Ammar DA, et al. Preclinical investigation of ab interno trabeculectomy using a novel dual-blade device. $\mathrm{Am}$ J Ophthalmol. 2013;155(3):524-529. doi:10.1016/j.ajo.2012.09.023

6. Tanito M, Sano I, Ikeda Y, et al. Microhook ab interno trabeculotomy, a novel minimally invasive glaucoma surgery, in eyes with open-angle glaucoma with scleral thinning. Acta Ophthalmol. 2016;94(5):e371-e372. doi:10.1111/aos.12888

7. Byszewska A, Konopińska J, Kicińska AK, et al. Canaloplasty in the treatment of primary open-angle glaucoma: patient selection and perspectives. Clin Ophthalmol. 2019;13:2617-2629. doi:10.2147/ OPTH.S155057

8. Tanito M, Sano I, Ikeda Y, et al. Short-term results of microhook ab interno trabeculotomy, a novel minimally invasive glaucoma surgery in Japanese eyes: initial case series. Acta Ophthalmol. 2017;95(5): e354-e360. doi:10.1111/aos.13288

9. Vinod K, Gedde SJ, Feuer WJ, et al. Practice preferences for glaucoma surgery. J Glaucoma. 2017;26(8):687-693. doi:10.1097/ IJG.0000000000000720

10. Chihara E, Nishida A, Kodo M, et al. Trabeculotomy ab externo: an alternative treatment in adult patients with primary open-angle glaucoma. Ophthalmic Surg. 1993;24:735-739.
11. Akimoto M, Tanihara H, Negi A, et al. Surgical results of trabeculotomy ab externo for developmental glaucoma. Arch Ophthalmol. 1994;112:1540-1544. doi:10.1001/archopht.1994.01090240046024

12. Iwao K, Inatani M, Tanihara H; Japanese Steroid-Induced Glaucoma Multicenter Study Group. Success rates of trabeculotomy for steroid-induced glaucoma: a comparative, multicenter, retrospective cohort study. Am J Ophthalmol. 2011;151:1047-1056. doi:10.1016/j. ajo.2010.11.028

13. Honjo M, Tanihara $\mathrm{H}$, Inatani $\mathrm{M}$, et al. External trabeculotomy for the treatment of steroid-induced glaucoma. J Glaucoma. 2000;9 (6):483-485. doi:10.1097/00061198-200012000-00011

14. Tanito M, Ohira A, Chihara E. Factors leading to reduced intraocular pressure after combined trabeculotomy and cataract surgery. J Glaucoma. 2002;11(1):3-9. doi:10.1097/00061198-20020200000002

15. Tanihara H, Negi A, Akimoto M, et al. Surgical effects of trabeculotomy ab externo on adult eyes with primary open angle glaucoma and pseudoexfoliation syndrome. Arch Ophthalmol. 1993;111:1653-1661. doi:10.1001/archopht.1993.01090120075025

16. Wada Y, Nakatsu A, Kondo T. Long-term results of trabeculotomy ab externo. Ophthal Surg. 1994;25:317-320.

17. ElMallah MK, Berdahl JP, Williamson BK, et al. Twelve-month outcomes of stand-alone excisional goniotomy in mild to severe glaucoma. Clin Ophthalmol. 2020;14:1891-1897. doi:10.2147/ OPTH.S256423

18. Tanito M, Ohira A, Chihara E. Surgical outcome of combined trabeculotomy and cataract surgery. J Glaucoma. 2001;10(4):302-308. doi:10.1097/00061198-200108000-00010

19. Dannheim R, Van der Zypen E. Clinical, functional and electron microscopic studies of the regeneration ability in the chamber angle of primate eyes following trabeculotomy. Graefes Arch Clin Exp Ophthalmol. 1972;184(3):222-247. doi:10.1007/BF00413297

20. Ito $S$, Nishikawa $M$, Tokura $T$, et al. Histopathological study of trabecular meshwork after trabeculotomy in monkeys. Nippon Ganka Gakkai Zasshi. 1994;98:811-819.

21. Johnstone M. The aqueous outflow system as a mechanical pump: evidence from examination of tissue and aqueous movement in human and non-human primates. J Glaucoma. 2004;13(5):421-438. doi:10.1097/01.ijg.0000131757.63542.24

22. Cha EDK, Xu J, Gong L, et al. Variations in active outflow along the trabecular outflow pathway. Exp Eye Res. 2016;146:354-360. doi:10.1016/j.exer.2016.01.008

23. Kinoshita-Nakano E, Nakanishi $H$, Ohashi-Ikeda $H$, et al. Comparative outcomes of trabeculotomy ab externo versus trabecular ablation ab interno for open angle glaucoma. Jpn J Ophthalmol. 2018;62(2):201-208. doi:10.1007/s10384-017-0559-0

24. Hamanaka T, Matsuda A, Sakurai T, et al. Morphological abnormalities of schlemm's canal in primary open-angle glaucoma from the aspect of aging. Invest Ophthalmol Vis Sci. 2016;57:692-706.

25. Mäepea O, Bill A. The pressures in the episcleral veins, schlemm's canal and the trabecular meshwork in monkeys: effects of changes in intraocular pressure. Exp Eye Res. 1989;49(4):645-663. doi:10.1016/ S0014-4835(89)80060-0

26. Rosenquist R, Epstein D, Melamed S, et al. Outflow resistance of enucleated human eyes at two different perfusion pressures and different extents of trabeculotomy. Curr Eye Res. 1989;8 (12):1233-1240. doi:10.3109/02713688909013902

27. Rohen JW, van der Zypen E. The phagocytic activity of the trabecular meshwork endothelium. An electron-microscopic study of the vervet. Graefes Arch Clin Exp Ophthalmol. 1968;175:143-160. doi:10.1007/ BF02385060

28. Widder RA, Lappas A, Rennings C, et al. Influence of oral anticoagulation on success rates and risk of bleeding events after iStent inject implantation combined with phacoemulsification. Graefes Arch Clin Exp Ophthalmol. 2020. doi:10.1007/s.417-020-04894-3 
29. Parikh HA, Bussel II, Schuman JS, et al. Coarsened exact matching of phaco-trabectome to trabectome in phakic patients: lack of additional pressure reduction from phacoemulsification. PLoS One. 2016;11(2):e0149384. doi:10.1371/journal.pone.014 9384

30. Berdahl JP, Gallardo MJ, ElMallah MK, et al. Six-month outcomes of goniotomy performed with the Kahook dual blade as a stand-alone glaucoma procedure. Adv Ther. 2018;35(11):2093-2102. doi:10.10 07/s12325-018-0803-0
31. Konopińska J, Kozera M, Kraśnicki P, et al. The effectiveness of first-generation iStent microbypass implantation depends on initial intraocular pressure: 24-month follow-up - prospective clinical trial. J Ophthalmol. 2020;8:164703. doi:10.1155/2020/8164703.eCollection

32. Chihara E, Hayashi K. Different modes of intraocular pressure reduction after three different nonfiltering surgeries and trabeculectomy. Jpn J Ophthalmol. 2011;55(2):107-114. doi:10.1007/s10384-0100923-9

\section{Publish your work in this journal}

Clinical Ophthalmology is an international, peer-reviewed journal covering all subspecialties within ophthalmology. Key topics include: Optometry; Visual science; Pharmacology and drug therapy in eye diseases; Basic Sciences; Primary and Secondary eye care; Patient Safety and Quality of Care Improvements. This journal is indexed on PubMed

Submit your manuscript here: https://www.dovepress.com/clinical-ophthalmology-journal
Central and CAS, and is the official journal of The Society of Clinical Ophthalmology (SCO). The manuscript management system is completely online and includes a very quick and fair peer-review system, which is all easy to use. Visit http://www.dovepress.com/ testimonials.php to read real quotes from published authors. 